\title{
Factors Affecting Management Accounting Practices in Malaysia
}

\author{
Sudhashini Nair ${ }^{1} \&$ Yee Soon Nian ${ }^{1}$ \\ ${ }^{1}$ Faculty of Business, Accounting and Management, SEGi University, Kota Damansara, Selangor, Malaysia \\ Correspondence: Sudhashini Nair, Yee Soon Nian, Faculty of Business, Accounting and Management, SEGi \\ University, Kota Damansara, 47810, Petaling Jaya, Selangor, Malaysia. E-mail: sudhashini@segi.edu.my
}

Received: June 29, 2017

doi:10.5539/ijbm.v12n10p177
Accepted: August 12, 2017 Online Published: September 17, 2017

URL: https://doi.org/10.5539/ijbm.v12n10p177

\begin{abstract}
Management accounting is the process of preparing management reports and accounts that provide accurate and timely, financial and statistical information to assist in management decision making. It is also known as the process of identifying, measuring, accumulating, analyzing, preparing, interpreting and communicating information to help managers fulfill the organization's objectives. Management accounting practices are used by organizational managers at various levels and at the same time, it gives managers the freedom of choice as there are no constraints, other than the cost of information collected relative to benefits of improved management decisions. Studies have found that there are factors that may affect management accounting practices. Literature has indicated that factors such as--organization size, intensity of market competition, level of qualification of accounting staff and advanced production technology--may affect management accounting practices. The objective of this research is to study the impact of these factors on management accounting practices in Malaysia. A total of 200 respondents from Klang Valley, Malaysia were involved in the survey using purposive sampling. The results of the study revealed that organization size and advanced production technology have significant relationships with management accounting practices.
\end{abstract}

Keywords: Management accounting practices, organization size, intensity of market competition, level of qualification of accounting staff and advanced production technology

\section{Introduction}

Rosmawati and Normah (2004) stated that Malaysia must continuously reinvent itself to ensure its sustainability in this competitive global economy. In 1995, many developing countries shifted to the generation of creation of value through the effective use of resources and technologies (Sunarni, 2013). In March 1998, the Financial and Management Accounting Committee (FMAC) and the International Federation of Accountants (IFAC) identified the field of organizational activity encompassed by management accounting has developed through four evolutionary stages (MIA, 2017). These four stages comprises of cost determination and financial control, information for management planning and control, reduction of waste of resources in business processes and creation of value through effective resources use. Hence the role of management accounting practices (MAPs) are important as the information provided to managers are relevant and useful in the sustainability of companies in today's competitive global market (Sunarni, 2013). MAPs are thus important in improving the organizations' performance and the profitability of companies (Sunarni, 2013).

MAPs have a significant effect on the performance of an organization (Abdel Al, \& McLellan, 2013). MAPs do not have any differences from one industry to another industry. Therefore, the type of industry does not have any impact on MAPs (Abdel Al, \& McLellan, 2013). Malaysian small and medium enterprises (SMEs) in the manufacturing sector have widely adopted MAPs such as budgeting and traditional costing (Ahmad, 2014). There are significant number of SMEs that have adopted MAPs such as financial and non-financial measures to assist in management decision making (Ahmad, 2014). However, SMEs are unlikely to adopt comprehensive MAPs in their firms due to the organization size.

Larger organizations are required to have sophisticated cost and management accounting systems in order to make decisions on the pricing and costing of their products (Ahmad, 2014). Organization size is included in this study as literature has found it to be relevant in MAPs (Albu \& Albu, 2012; Haldma, \& Laats, 2002). Smaller companies prefer to adopt traditional MAPs instead of modern MAPs (Haldma, \& Laats, 2002). However as an organization becomes larger, managers need to handle greater amounts of quantities and information. This is 
because larger organizations have larger amounts of resources and are in a dominant position to control their environment with the use of MAPs (Albu \& Albu, 2012). Furthermore, in countries such as Estonia, MAPs were important when the size of manufacturing companies grew. This is because managers required more details to measure the performance of their companies with regards to the sales region and clients groups (Haldma, \& Laats, 2002). Organization size as such may have an impact on MAPs as large organizations tend to adopt MAPs compared to SMEs.

The intensity of market competition also plays an important role in encouraging companies to adopt MAPs. As time goes by and as market competition increases; MAPs are important as it allows companies to compete with their competitors effectively and it allows companies to make better decisions (Ahmad, 2014). In addition, MAPs in companies today face intense competition from internal factors and external factors. Internal factors are factors such as technology and strategy of the company while external factors features the external environment at the level of business and accounting that shape the internal system (Ahmad, 2014).

Qualified accounting staff are also important to an organization as the knowledge of accounting staff would affect the success, growth and sustainability of the organization (Brown, Booth, \& Giacobbe, 2004). Larger organizations normally have accounting and finance department (Ismail \& King, 2007). Therefore, large firms hire qualified accounting staffs to use MAPs for internal reporting and to assist managers in the decision making process (Ismail \& King, 2007). In terms of the SMEs context, MAPs applied by qualified accounting staffs may have a significant impact to the organization's productivity and growth (Collis \& Jarvis, 2002). Therefore, the qualification of accounting staff is one of the factors that might affect the adoption of MAPs in an organization. On the other hand, the shortage of qualified accountants may serve as a crucial aspect, as far as the application of contemporary management accounting techniques are concerned.

The production process in a manufacturing company determines the type of costing system used by organizations. Furthermore, technology constraints from the production process may have an effect on designing of a new accounting system in manufacturing companies (Haldma, \& Laats, 2002). As such, the manufacturing process requires MAPs to become more complex and sophisticated (Haldma, \& Laats, 2002). Companies using modern technology in the production activities have an impact on MAPs mainly in larger companies but not for SMEs. Production technology is limited to SMEs because larger firms are highly dependent on technology to assist their production activities compared with SMEs. In 21st century, the trends for business environment and technology has been evolving rapidly and has been widely disseminated so that larger firms are able to follows the trends but, SMEs find it difficult to follow the trends due to lack of resources in adopting the current technology (Ahmad, 2012).

The review of literature has emphasized that these four factors--organization size, intensity of market competition, level of qualification of accounting staff and advanced production technology-- have been commonly cited as factors affecting MAPs, however relatively few studies have empirically tested these four factors with MAPs. Studies investigating the impact of these four factors with MAPs are scarce especially in Malaysia, hence to address this research gap, the present study aims to examine the relationships of these four factors--organization size, intensity of market competition, level of qualification of accounting staff and advanced production technology-- with MAPs in Malaysia

\section{Literature Review}

Otley (1980) stated that there was no reference about contingency theory before 1970s. However, Drury (2004) stated that in the mid of 1970 s, contingency theory was assumed that optimal management accounting was applicable to all organizations. Contingency theory approach however advocates that there is no one 'best' design for management accounting but contingency theory depends on the situational factors. Garrison, Noreen and Seal (2006) mentioned that contingency theories in management accounting are the class of behavioral theory that contend that the leadership style that is effective in some situations may not be successful in others. It was found that potential contingency factors that may explain the effectiveness of management control system includes environment, technology, size, strategy and culture (Garrison, et al., 2006; Otley, 1980). This study examines four factors namely-- organization size, intensity of market competition, level of qualification of accounting staff and advanced production technology—with MAPs with the objective of studying its significant impact on MAPs in Malaysia.

\subsection{Relationship between Organization Size and Management Accounting Practices}

Organization size is defined as number of employees in the organization, however organization size can also be measured by the paid up capital of the organization (Tuanmat, \& Smith, 2011). Ahmad (2012) examined 110 Malaysian companies in the manufacturing sector. The findings of the study revealed that organization size has a 
significant impact on MAPs in business operations because larger firm have greater resources to facilitate MAPs. The study also found that larger firms required more comprehensive MAPs compared with SMEs.

A study by Ismail and Mahmoud (2012) that examined organization size with MAPs in Egyptian manufacturing firms found that only few manufacturing firms that have adopted modern MAPs because modern MAPs are sophisticated to Egyptian manufacturing firms. Also, majority of the manufacturing firms in Egypt prefer to adopt traditional MAPs because traditional MAPs are simple and are convenient to use. Finally, in the research by Mbawuni and Anertey (2014) examining MAPs in telecommunication companies in Ghana, it was found that the extent of the usage and reasons for adoption of MAPs in Ghana depended on the nature and organization size.

\subsection{Relationship between Intensity of Market Competition and Management Accounting Practices}

Intensity of market competition is defined as one organization competing with another organization in terms of product, services and prices in the external environment (Cadez \& Guilding, 2008). Ahmad (2012) mentioned that intensity of market competition is an external factor of competition and managers need to gain knowledge and experience regarding new costing system to compete in an intense market competition. Leite, Fernandes, and Leite (2015) examined the market competition faced by organizations that have adopted MAPs. The authors found that MAPs are required for the organization due to complexity of the business environment and that MAPs assist organizations to determine the resources incurred in each production process. Furthermore, Luther and Longden's (2001) study on MAPs in South Africa found that MAPs change due to the volatility of the market competition faced by companies.

Haldma and Laats (2002) examined the impact of the intensity of market competition on MAPs of manufacturing company in Estonia. The findings of the study revealed that there is a significant relationship between intensity of market competition on MAPs as the external environment aspect affected the nature of the accounting system. Tuanmat and Smith (2011) studied the impact of business environment on MAPs of manufacturing company in Malaysia. The results of the study indicated that there is a positive significant relationship between the external business environments with MAPs. Also the study found these companies' using MAPs in their external business environment affected the performance of their companies.

\subsection{Relationship between Level of Qualification of Accounting Staff and Management Accounting Practices}

Level of qualification of accounting staff is defined as the knowledge obtained by an accountant to perform some activity in their organization. Level of qualification according to Abdel-Kader and Luther (2008) is essential and crucial for accountants. Abdel-Kader and Luther (2008) examined the relationship of the level of qualification of accounting staff on MAPs in United Kingdom (UK). The results indicated that the level of qualification of accounting staff will differ between sophistication of management accounting and organization.

Haldma and Laats's (2002) study on accounting staff on MAPs in Estonian manufacturing companies found that there is a significant relationship between the level of qualification of accounting staff and MAPs. Also the authors found that there are a lot of accounting staff that did not have proper knowledge on how to use the accounting information. Ahmad (2012) examined the relationship between the level of qualification of accounting staff and MAPs in Malaysian SMEs. The author found that the level of qualification of accounting staff had a significant impact on MAPs in Malaysian SMEs. Furthermore, the study found that the education level of accounting staff significantly influenced the preparing and usage of accounting information.

\subsection{Relationship between Advanced Production Technology and Management Accounting Practices}

Advanced production technology is defined as an innovative technology used to improve the performance of a manufacturing company (Ahmad, 2012). According to Leite et al.'s (2015) study on the relationship between advanced technology of the production and MAPs, it was found that technology in textile industry evolve rapidly through recent decades. The technology was reflected in the stage of manufacturing process which is electronics and automation. The results indicated that there is a significant impact between advanced production technology and MAPs.

Advanced production technology assist organizations to remain in the competitive advantage in the market. Abdel-Kader and Luther (2008) investigated the relationship of advanced production technology and MAPs based on level of sophistication. The result of the study showed that the difference in the management accounting sophistication are significantly explained by production technology. Ahmad (2012) analyzed advanced production technology and MAPs in SMEs. The result showed that there is significant influence between advanced production technology and certain MAPs such as costing and performance evaluation. 
Furthermore, the author found that modern technology has an impact on MAPs in larger firm but not for SMEs. This is because advance production technology supported larger firms in their production process activities.

\section{Figure 1 below Depicts the Research Model of the Study Together with the Associated Hypotheses}

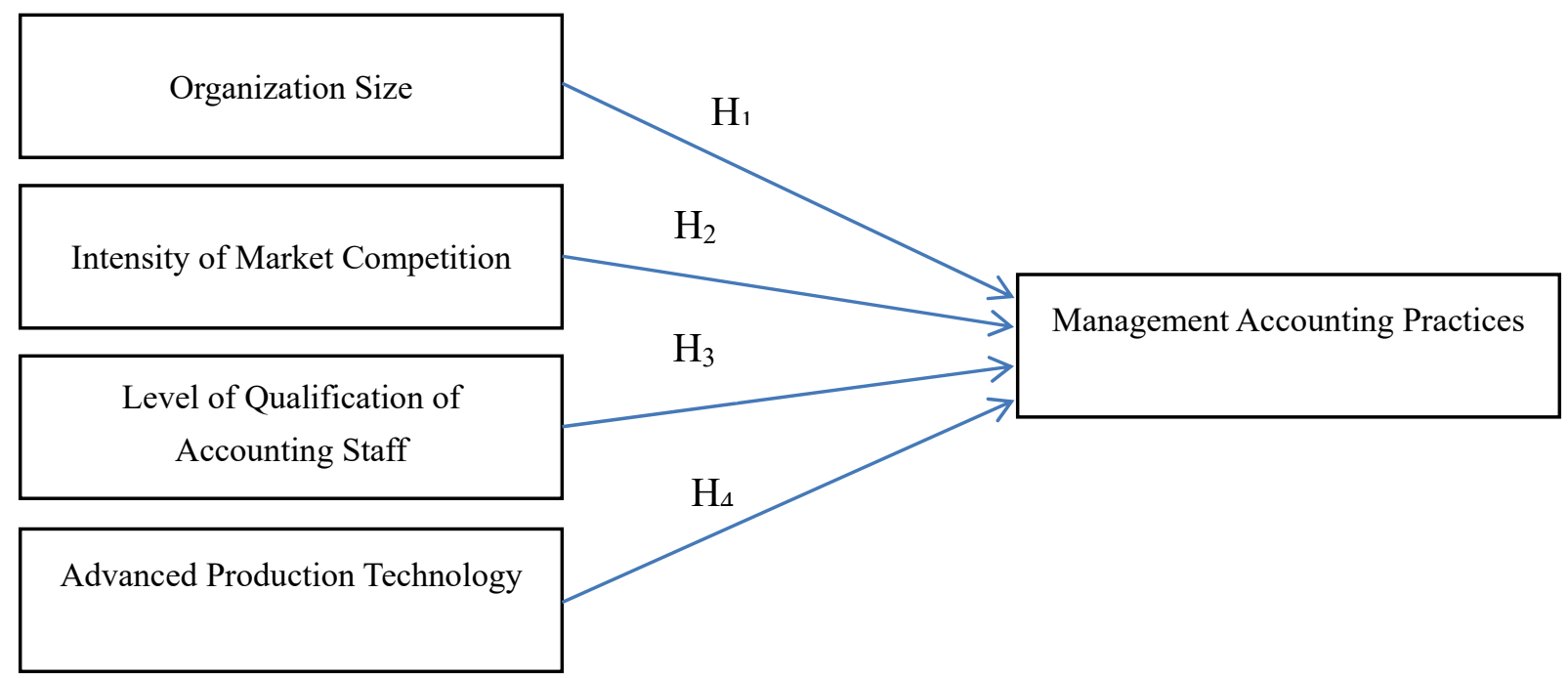

Figure 1. The research model

\section{Research Hypotheses}

$\mathrm{H}_{1}$ : There is a significant positive relationship between organization size and management accounting practices in Malaysia.

$\mathrm{H}_{2}$ : There is a significant positive relationship between intensity of market competition and management accounting practices in Malaysia.

$\mathrm{H}_{3}$ : There is a significant positive relationship between level of qualification of accounting staff and management accounting practices in Malaysia.

$\mathrm{H}_{4}$ : There is a significant positive relationship between advanced production technology and management accounting practices in Malaysia.

\section{Research Methodology}

\subsection{Measurement and Collection of Data}

In this research, the quantitative approach is employed and data was collected using non-probability sampling method, particularly purposive sampling technique (Hair, Black, Bablin, \& Anderson, 2010; Sekaran, 2006). Purposive sampling technique is where the researcher collected the information from a specific group of people (Sekaran, 2006). Self-administered questionnaires were used to collect data from 200 respondents. The questionnaire in this research comprised into two sections. The first part was designed to collect respondents' demographic information comprising of gender, age, marital status and education level. The second part of the questionnaire consisted of the measurement scales of the variables in study. The questionnaire utilized several measures. A five item scale for organization size and level of qualification of accounting staff was adopted from Ahmad (2012). While a five item scale for intensity of market competition and advance production technology was adopted from Tuanmat and Smith (2011). Each of the variables in study was measured using a 5-point Likert scale which was used to show (1) "Strong Disagree", (2) "Disagree", (3) "Slightly Agree", (4) "Agree", (5) "Strongly Agree".

The data from this study was computed using SPSS. The researchers performed a pilot test in which the researchers derived the questionnaires from the initial 20 respondents in order to ensure the items in each variable are reliable. When the results of pilot tests were found to be reliable, the researchers distributed the remaining 180 questionnaires to the respondents. The results of reliability tests in this research was more than 0.70 (Hair et al., 2010; Sekaran, 2006). In addition, the normality was done by using the Z-score calculation in which the value was 2.343 lying within $-3.29<Z>3.29$. The curve graph from the histogram of this study based on the data collected was normal. Moreover, linearity test was used to examine if the questionnaires were fairly 
distributed by using scatter plot graph. The randomized pattern of the scatter plot indicated the linearity assumption was met. The respondents' demographic profile is summarized in Table 1

\subsection{Demography of Respondents}

Table 1. Gender, Age, Marital Status and Education Level

\begin{tabular}{llll}
\hline Types & Categories & Frequency & Percent \\
\hline Gender & Male & 110 & 55.0 \\
& Female & 90 & 45.0 \\
Age & $18-22$ years old & 25 & 12.5 \\
& $23-27$ years old & 65 & 32.5 \\
& $28-33$ years old & 66 & 33.0 \\
Marital Status & 34 years old and above & 44 & 22.0 \\
& Single & 135 & 67.5 \\
Education Level & Married & 65 & 32.5 \\
& Diploma & 16 & 8.0 \\
& Degree & 103 & 51.5 \\
& Master & 29 & 14.5 \\
& Professional Qualification & 52 & 26.0 \\
\hline
\end{tabular}

\section{Data Analysis}

\subsection{Pearson Correlation}

Pearson correlation test was used to examine the correlation between each independent variables with the dependent variable. The results of the correlation test shows organization size is 0.573 , intensity of market competition is 0.537 , level of qualification of accounting staff is 0.604 and advanced production technology is 0.635. The results indicate that organization size and intensity of market competition has a moderate positive correlation with MAPs while level of qualification of accounting staff and advanced production technology has a fairly high positive correlation with MAPs. Please refer to Table 2 for the results of the Pearson Correlation test

Table 2. Results of the Pearson correlation test

\begin{tabular}{|c|c|c|c|c|c|c|}
\hline & & $\begin{array}{l}\text { Management } \\
\text { Accounting } \\
\text { Practices } \\
\end{array}$ & $\begin{array}{l}\text { Organization } \\
\text { Size }\end{array}$ & $\begin{array}{l}\text { Intensity of } \\
\text { Market } \\
\text { Competition }\end{array}$ & $\begin{array}{l}\text { Level of } \\
\text { Qualification of } \\
\text { Accounting Staff }\end{array}$ & $\begin{array}{l}\text { Advanced } \\
\text { Production } \\
\text { Technology }\end{array}$ \\
\hline Management & Pearson & 1 & .573 & .537 & .604 & .635 \\
\hline Accounting & Correlation & & & & & \\
\hline \multirow[t]{2}{*}{ Practices } & Sig. (2 tailed) & & .000 & .000 & .000 & .000 \\
\hline & $\mathrm{N}$ & 200 & 200 & 200 & 200 & 200 \\
\hline
\end{tabular}

\subsection{Multiple Regression Analysis}

Multiple regression analysis was carried out to test the variables in this research in order to examine the hypotheses (Cooper \& Schindler, 2008). Multiple regression analysis examines the regression coefficients for each independent variables and dependent variable. Durbin-Watson in this research is 2.194 which is within the required range of 1 to 3 (Sekaran, 2006). The result of Durbin-Watson indicates that there is no autocorrelation among residuals (homoscedasticity). This means the data collected in this study shows that there is no inter-item correlation. Besides that, the result of R Square is 0.448 or $44.8 \%$. This indicate that $44.8 \%$ of the total variance in the dependent variable is explained by the total independent variables. Thus, the remaining $55.2 \%$ might be accounted by other variables that are not included in this research. Table 3 shows the model summary. 
Table 3. Model Summary

\begin{tabular}{llllll}
\hline $\begin{array}{l}\text { Model Summary } \\
\text { Model }\end{array}$ & R & R Square & Adjusted R Square & Std. Error of the Estimate & Durbin-Watson \\
\hline 1 & $.669^{\mathrm{a}}$ & .448 & .437 & .51992 & 2.194 \\
\hline
\end{tabular}

ANOVA is a statistical tool used for hypothesis testing (Sekaran, 2006). According to ANOVA analysis, the model is statistically significant as the p-value of 0.000 is below than 0.05 (Basso, Pesarin, Salmaso, \& Solari, 2009). This shows that there is a significant relationship between dependent variable and independent variables. The F value of 39.547 indicates that the conceptual model is strongly significant and the variation is not totally accounted by possibility. Table 4 shows the analysis of variance (ANOVA) in this study.

Table 4. Analysis of variance (ANOVA) in this study

\begin{tabular}{lllllll}
\hline ANOVA $^{\mathbf{a}}$ & & & & & \\
\hline Model & & Sum of Squares & Df & Mean Square & F & Sig. \\
1 & Regression & 42.761 & 4 & 10.690 & 39.547 & $.000^{\text {b }}$ \\
& Residual & 52.711 & 195 & .270 & & \\
& Total & 95.472 & 199 & & & \\
\hline
\end{tabular}

The results of the coefficients shows that the significant value for intensity of market competition and level of qualification of accounting staff are greater than 0.005 , which makes it not significant. However, the significant value for organization size and advanced production technology are lower than 0.005 , which makes it significant. Based on the research, the hypothesis for organization size and advanced production technology are accepted while the hypothesis for intensity of market competition and level of qualification of accounting staff are rejected. Table 5 is the results of the coefficients while Table 6 shows the summary of the hypotheses results.

Table 5. Results of the coefficients

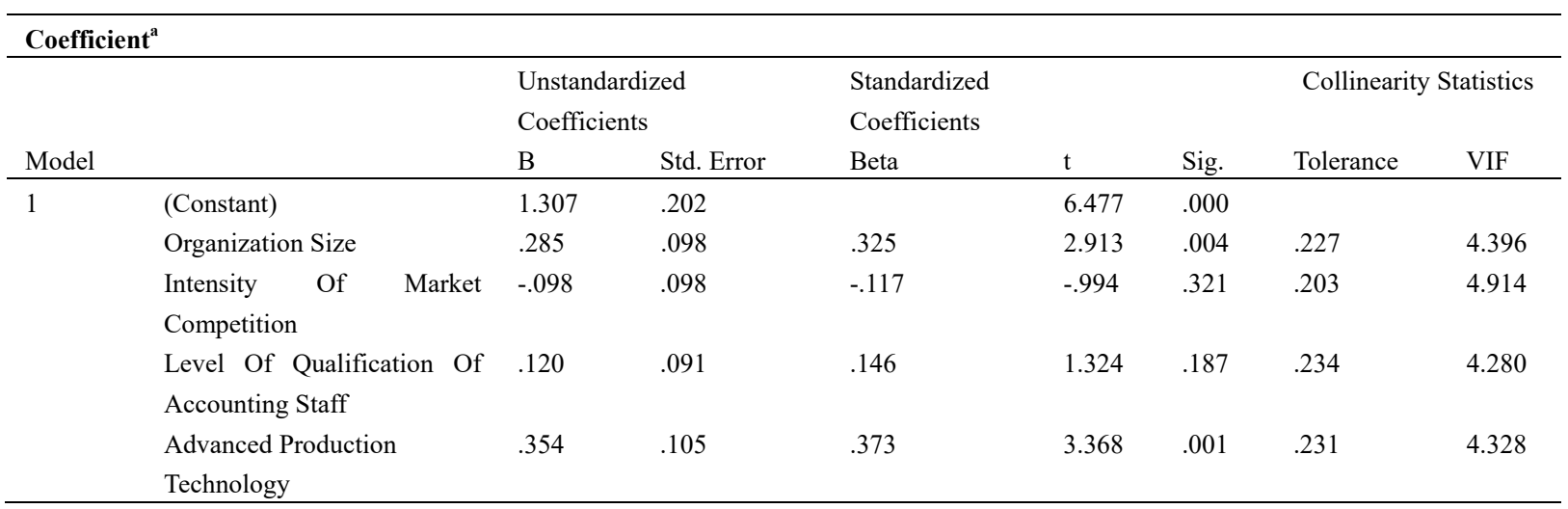

\subsection{Hypotheses Result}

Table 6. Summary of the hypotheses result

\begin{tabular}{llll}
\hline & Hypothesis & Significant & $\begin{array}{c}\text { Result } \\
\text { (Beta, } \beta \text { ) }\end{array}$ \\
\hline $\mathrm{H}_{1} \quad \begin{array}{l}\text { There is a significant positive relationship between organization size } \\
\text { and management accounting practices in Malaysia. }\end{array}$ & Accepted \\
$\mathrm{H}_{2} \quad \begin{array}{l}\text { There is a significant positive relationship between intensity of market } \\
\text { competition and management accounting practices in Malaysia. }\end{array}$ & Rejected \\
$\mathrm{H}_{3} \quad \begin{array}{l}\text { There is a significant positive relationship between level of } \\
\text { qualification of accounting staff and management accounting practices } \\
\text { in Malaysia. }\end{array}$ & Rejected \\
$\begin{array}{l}\text { There is a significant positive relationship between advanced } \\
\text { production technology and management accounting practices in } \\
\text { Malaysia. }\end{array}$ & Accepted \\
\hline
\end{tabular}




\section{Discussion of Findings}

The study was undertaken to examine the relationships of four factors--organization size, intensity of market competition, level of qualification of accounting staff and advanced production technology-- with MAPs in Malaysia. The research findings revealed that MAPs are affected by organization size and advanced production technology. As per previous research, organization size was found to have a positive and significant relationship with MAPs (Ahmad, 2012; Mbawuni \& Anertey, 2014; Ismail \& Mahmoud, 2012). As such, more attention should be given by the government, public and private sector as well as accounting bodies to develop appropriate policies and procedures to allow for better adoption of MAPs. Resources such as training and development may be provided to better understand the usage and application of MAPS for larger organizations. One of the benefits of MAPs for larger firms is that there would be the better assessment of MAPs such as ROI-Return on Investment, RI-Residual Income, EVA-Economic Value Added in measuring and comparing a company's divisional performance.

Lastly advanced production technology has a significant positive relationship with MAPs similar to the findings of Abdel-Kader and Luther (2008), Ahmad (2012) and Leite et al.'s (2015). Management should encourage a team approach when adopting MAPs. Product designers, production engineers and the finance department should work closely with management in order to ensure the right MAPs are applied in their planning, controlling of cost, decision making and appraising of performance when advance technologies are used in the production process.

There are a few recommendations for future researchers, firstly, future researcher could include a broader based population. Also, future research can investigate other factors that can affect MAPs such as complexity of processing system and perceived environmental uncertainty. Also, it would be interesting to see whether there is a changing effect over time by conducting a longitudinal study-to examine if there is an increase importance of these factors on MAPs

In conclusion, the findings of this study have contributed to the existing literature on the understanding of factors that affects MAPs (Ahmad, 2012; Abdel-Kader \& Luther, 2008). Organization size and advance production technology seem to play a much more significant role MAPs. The results from this study carry an important message to various parties - the policy makers, the government, professional bodies--that policies and practices have to be installed and implemented in a synchronized way to improve MAPs in Malaysia. The researchers believes that this research could be an important contribution to broaden the knowledge and understanding on the factors that affects MAPs. Besides that, this research may help economists and accountants to gain new knowledge about MAPs. Furthermore, professional bodies will benefit from this as various policies can be implemented to encourage the adoption and usage of MAPs.

\section{References}

Abdel Al, S. F., \& McLellan, J. D. (2013). Strategy and management accounting practices alignment and its effect on organizational performance. Journal of Accounting - Business \& Management, 20(1)1, 1-27.

Abdel-Kader, M. and Luther, R. (2008). The impact of firm characteristics on management accounting practices: A UK-based empirical analysis. British Accounting Review, 40 (1). pp. 2-27. ISSN 08908389. http://dx.doi.org/10.1016/j.bar.2007.11.003

Ahmad, K (2012). Factors explaining the extent of use of management accounting practices in Malaysian medium firms. Asean Entrepreneurship Conference 2012.

Ahmad, K. (2014). The adoption of management accounting practices in Malaysian small and medium-sized enterprise. Asian Social Science, 10(2), 236-249.

Albu, N., \& Albu, C. (2012). Factors associated with the adoption and use of management accounting techniques in developing countries: The case of Romania. Journal of International Financial Management \& Accounting, 23(3), 245-276.

Basso ,D. Pesarin, F., Salmaso, S., \& Solari, A. (2009). Permutation Tests for Stochastic Ordering and ANOVA: Theory and Applications with R. US: New York.

Brown, A., Booth, P., \& Giacobbe, F. (2004). Technological and organizational influences on the adoption of activity-based costing in Australia. Accounting and Finance, 44(3), 329-356.

Cadez, S., \& Guilding, C. (2008). An exploratory investigation of an integrated contingency model of strategic management accounting. Accounting, Organization and Society, 33, 836-863.

Collis, J., \& Jarvis, R. (2002). Financial information and the management of small private companies. Journal of 
Small Business and Enterprise Development, 9(2), 100-110.

Cooper, C. R., \& Schindler, P. S. (2008). Business Research Methods (10th ed.). Boston: McGraw-Hill.

Drury, C. (2004) Management and Cost Accounting (6th ed.). London: Thomson Learning.

Garrison, R., Noreen, E.W., \& Seal, W. (2006). Management Accounting. McGraw-Hill.

Haldma, T., \& Laats, K. (2002). Influencing contingencies on management accounting practices in Estonian manufacturing companies. University of Tartu - Economics and Business Administration Working Paper No. 13

Hair, B. B., \& Anderson. (2010). Multivariate Data Analysis (7th ed.). US: Pearson Prentice Hall.

Ismail, N. A., \& King, M. (2007). Factors influencing the alignment of accounting information systems in small and medium sized Malaysian manufacturing firms. Journal of Information Systems and Small Business, 1(2), $1-20$.

Ismail, T. H., \& Mahmoud, N. M. (2012). The influence of organizational and environmental factors on cost systems design in Egypt. British Journal of Economics, Finance and Management Science, 4(2), 31-51.

Leite, A. A, Fernandes, P. O., \& Leite, J. M. (2015). Contingent factors that influence the use of management accounting practices in the Portuguese textile and clothing sector. The International Journal of Management Science and Information Technology. Special Issue: Spanish-Portuguese Scientific Management Conference, (59-77).

Luther, R. G., \& Longden, S. (2001). Management accounting in companies adapting to structural change and volatility in transition economies: A South African study. Management Accounting Research, 12, 299-320.

MIA (2017) Malaysian Institute of Accountant. Member Statistics. Retrieved from http://www.mia.org.my/v1/membership/services/statistics/member_statistics.aspx

Mbawuni, J., \& Anertey, A. (2014). Exploring management accounting practices in emerging telecommunication market in Ghana. Accounting and Finance Research, 3(4), 71-85.

McLellan, J. D. (2014). Management accounting theory and practice: Measuring the gap in United States Business. Journal of Accounting - Business \& Management, 21(1), 53-68.

Otley. D. T. (1980). The contingency theory of management accounting: Achievement and Prognosis. Accounting, Organizations and Society, 5(4), 413-428.

Rosmawati, M., \& Normah. (2004). The current state of management accounting practice in selected Malaysian companies: An empirical evidence. International Business Management Conference.

Sekaran. (2006). Research Methods for Business: A skill building approach (4th ed.). US: Wiley.

Sunarni, C. W. (2013). Management Accounting Practices and the Role of Management Accountant: Evidence from Manufacturing Companies throughout Yogyakarta, Indonesia. Review Journal of Management, 18(2), 233- 248

Tuanmat, T. Z., \& Smith, M. (2011). Changes in management accounting practices in Malaysia. Asian Review of Accounting, 19(3), 221-242.

\section{Copyrights}

Copyright for this article is retained by the author(s), with first publication rights granted to the journal.

This is an open-access article distributed under the terms and conditions of the Creative Commons Attribution license (http://creativecommons.org/licenses/by/4.0/). 